\title{
TUBERCULOSIS OF THE BREAST- A SURGICAL PERSPECTIVE
}

\author{
Sanjay Sharma1, Ratnakar Sharma², Akashdeep Singh ${ }^{3}$
}

${ }_{1}^{1}$ Assistant Professor, Department of General Surgery, GMC, Jammu, Jammu and Kashmir, India.

${ }^{2}$ Associate Professor, Department of General Surgery, GMC, Jammu, Jammu and Kashmir, India.

${ }^{3}$ Lecturer, Department of General Surgery, GMC, Jammu, Jammu and Kashmir, India.

\section{BACKGROUND}

Tuberculosis of the breast is a rare entity. Incidence of breast tuberculosis in Western World is $<0.1 \%$ of the breast lesions examined histopathologically. The overall incidence in developing countries is approximately $3 \%$ of all the surgically treated breast diseases. The diagnosis of tuberculosis of breast requires a variety of microbiological, histopathological and radiographic investigations. Tuberculosis of breast is treated primarily with anti-tubercular drugs along with surgical intervention in some of the patients.

Aims and Objectives- To evaluate the clinical spectrum of tuberculosis of breast. To evaluate the role of various diagnostic modalities and outcome of treatment in tuberculosis of breast.

\section{MATERIALS AND METHODS}

A retrospective descriptive study of clinical records of 1208 patients was done, out of which 30 patients managed for breast tuberculosis over a period of five years, i.e. January 2013 to December 2017 in the Department of General Surgery, Government Medical College, Jammu formed the study group. The patients suspected of having breast tuberculosis were diagnosed on the basis of clinical features and various diagnostic modalities/ investigations like mammography, ultrasonography of breast, FNAC, histopathological examinations, ZN staining for AFB and mycobacterial culture apart from routine investigations. All patients were treated successfully with antitubercular therapy and surgery [if required].

\section{RESULTS}

All the patients having been diagnosed with tuberculosis of breast were treated with ATT alone or ATT along with surgical intervention. The outcome of the treatment in all the cases was satisfactory.

\section{CONCLUSION}

Tuberculosis of breast is a disease of clinical suspicion. A variety of diagnostic modalities are needed to establish the diagnosis. ATT is the mainstay of treatment with surgical intervention needed in some cases.

\section{KEY WORDS}

Tuberculosis, Diagnostic, ATT, Treatment.

HOW TO CITE THIS ARTICLE: Sharma S, Sharma R, Singh A. Tuberculosis of the breast- a surgical perspective. J. Evolution Med. Dent. Sci. 2018;7(24):2861-2864, DOI: 10.14260/jemds/2018/645

\section{BACKGROUND}

Tuberculosis of breast is an uncommon disease. Sir Astley Cooper in 1829 recorded first case of breast tuberculosis and called it as "Scrofulous Swelling of the Bosom.1" Breast tuberculosis is rare in the Western Countries, incidence being $<0.1$ percent of the breast lesions examined histologically. ${ }^{2}$ With the global spread of HIV, increase in incidence of mammary tuberculosis has been noted. Breast tuberculosis is uncommon even in countries where incidence of tuberculosis is high. In developing countries where tuberculosis is endemic, the incidence is $0.3-5 \%{ }^{3}$ Breast tuberculosis accounts for up to $3 \%$ of all surgically treatable breast diseases in India. ${ }^{4}$ Bilateral involvement is even more rare.

'Financial or Other Competing Interest': None.

Submission 21-05-2018, Peer Review 02-06-2018,

Acceptance 04-06-2018, Published 11-06-2018.

Corresponding Author:

Dr. Ratnakar Sharma,

Associate Professor

Department of General Surgery,

Government Medical College,

Bakshi Nagar, Jammu-180001,

Jammu and Kashmir, India.

E-mail: ratnakarsharma111@gmail.com

DOI: $10.14260 /$ jemds $/ 2018 / 645$
The diagnosis is difficult because of non-specific clinical and radiological findings. It can be classified as primary and secondary. Primary involvement is tuberculosis infection confined only to the breast and is extremely uncommon. Secondary involvement is when there is co-existing tuberculosis lesion elsewhere in the body. The major routes of spread are haematogenous, lymphatic and contagious from the pleura and chest wall. Lymphatic spread is most common and 50 - 75 percent of patients have involvement of axillary lymph nodes at the time of presentation. ${ }^{5}$ Due to proximity of axillary nodes, upper outer quadrant of breast is the most frequently involved site.

In the present study, an attempt was made to describe in detail the various clinical manifestations. The diagnostic and treatment modalities were used for diagnosing and treating patients having tuberculosis of breast.

\section{MATERIALS AND METHODS}

A retrospective descriptive study of clinical records of 1208 patients was done, out of which 30 patients managed for breast tuberculosis over a period of five years, i.e. January 2013 to December 2017 in the Department of General Surgery, Government Medical College Jammu formed the study group. The patients suspected of having breast tuberculosis were diagnosed on the basis of clinical features 
and various diagnostic modalities/ investigations like mammography, ultrasonography of breast, FNAC, histopathological examinations, Ziehl-Neelsen staining for AFB and mycobacterial culture apart from routine investigations. All patients were treated successfully with antitubercular therapy and surgery [if required].

\section{Objectives}

To evaluate the clinical spectrum of tuberculosis of breast. To evaluate the role of various diagnostic modalities and outcome of treatment in tuberculosis breast.

\section{RESULTS}

\begin{tabular}{|c|c|c|}
\hline Age Group & No. of Patients & Percentage (\%) \\
\hline 21-30 years & 17 & 56.7 \\
\hline $31-40$ years & 10 & 33.3 \\
\hline 41-50 years & 2 & 6.7 \\
\hline $51-60$ years & 1 & 3.3 \\
\hline Total & 30 & 100 \\
\hline
\end{tabular}

The youngest patient was 24 years old and the oldest was 54 years old. The mean age of patients was 31 years. Out of the 30 patients, $29(96.7 \%)$ were females and 1 (3.3\%) was male. The male patient was 34 years old with past history of being treated for pulmonary tuberculosis. Most commonly affected age group was 21 - 30 years [Table 1].

Out of 29 female patients, twenty-seven were premenopausal, two were post-menopausal, two were pregnant, five lactating, five nulliparous and rest of the 15 female patients were multiparous. All the patients in our study group were married.

\begin{tabular}{|c|c|c|}
\hline Clinical Presentation & Number & Percentage (\%) \\
\hline Breast lump & 16 & 53.3 \\
\hline Breast abscess & 7 & 23.4 \\
\hline $\begin{array}{l}\text { Non-healing ulcers/sinuses } \\
\text { with underlying lump/abscess }\end{array}$ & 5 & 16.7 \\
\hline $\begin{array}{l}\text { Mastalgia with generalised } \\
\text { breast swelling and } \\
\text { tenderness }\end{array}$ & 1 & 3.3 \\
\hline Nipple discharge & 1 & 3.3 \\
\hline \multicolumn{3}{|c|}{ Table 2. Clinical Presentation of Patients } \\
\hline
\end{tabular}

Duration of symptoms ranged from 3 months to 2 years. Symptoms included breast pain, breast lump, breast abscess, ulcer, mastalgia, nipple discharge and multiple sinuses over breast skin [Table 2]. Most common site of breast lump was upper outer quadrant. Constitutional symptoms like fever, night sweats, weight loss or generalised weakness were present in five patients only. Bilateral breast involvement was seen in one patient only. There was no history of trauma in any patient. There was history of old treated pulmonary tuberculosis in two patients and past history of cervical tubercular lymphadenitis in one patient. One patient had previous history of breast abscess drained six years back. Ipsilateral axillary lymph nodes were palpable in three patients and one patient had concomitant active pulmonary tuberculosis.

\begin{tabular}{|c|c|c|}
\hline $\begin{array}{c}\text { Diagnostic } \\
\text { Modality }\end{array}$ & $\begin{array}{c}\text { Number of } \\
\text { Patients [N] }\end{array}$ & $\begin{array}{c}\text { Result [Positive/ } \\
\text { Conclusive] }\end{array}$ \\
\hline FNAC & 29 & 16 \\
\hline Biopsy & 13 & 13 \\
\hline $\begin{array}{c}\text { Mycobacterial } \\
\text { culture }\end{array}$ & 7 & 1 \\
\hline $\begin{array}{c}\text { Ziehl-Neelsen } \\
\text { staining }\end{array}$ & 7 & 1 \\
\hline Mammography & 22 & Inconclusive \\
\hline \multicolumn{2}{|c|}{ Table 3. Diagnostic Modalities } \\
\hline
\end{tabular}

Tissue biopsy of suspected lesions of the breast with histopathological examination was the most conclusive diagnostic modality for diagnosing tuberculosis of breast followed by FNAC, mycobacterial culture and Ziehl-Neelsen staining [Table 3].

\begin{tabular}{|c|c|c|}
\hline Treatment & No. of Patients & Percentage (\%) \\
\hline ATT only & 10 & 33.3 \\
\hline $\begin{array}{c}\text { Primary excision of } \\
\text { lump with ATT }\end{array}$ & 11 & 36.7 \\
\hline $\begin{array}{c}\text { Incision drainage of } \\
\text { breast abscess with } \\
\text { ATT }\end{array}$ & 7 & 23.3 \\
\hline $\begin{array}{c}\text { Excision of residual } \\
\text { lump after ATT }\end{array}$ & 2 & 6.7 \\
\hline \multicolumn{2}{|c|}{ Table 4. Treatment } \\
\hline
\end{tabular}

Treatment of breast tuberculosis with ATT followed guidelines used for extrapulmonary tuberculosis [Table 4]. We used four drugs rifampicin [R], isoniazid [H], ethambutol [E] and pyrazinamide [Z] in intensive phase for first two months followed by two drugs rifampicin and isoniazid for another four months. All the patients responded to ATT and were followed up for six months after completion of treatment and were disease free.

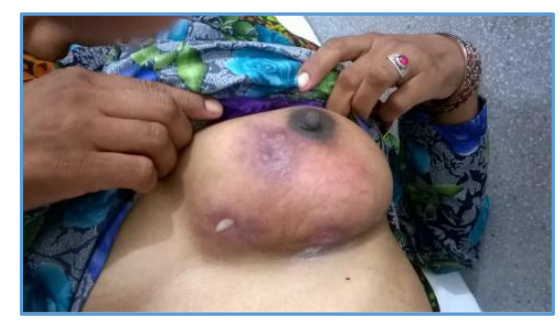

Photograph 1. Tuberculous Breast Sinuses

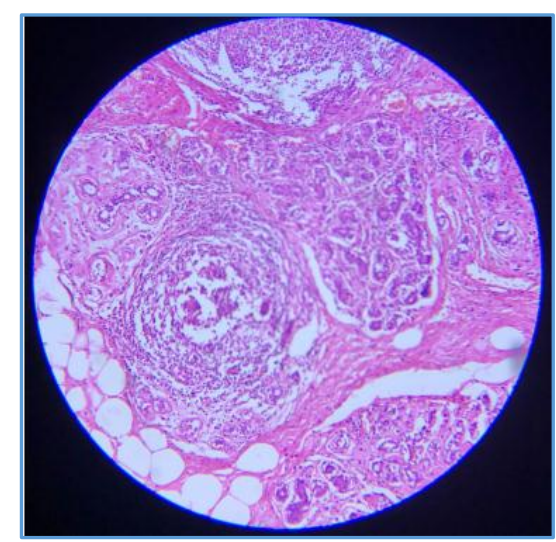

Photograph 2. Microscopic View showing Epithelioid Granulomas with Multinucleate Giant Cells and surrounding Normal Breast Tissue 


\section{DISCUSSION}

Tuberculosis of breast is a rare clinical entity requiring clinical acumen and various investigations for diagnosis. In our study out of 1208 patients treated for various breast diseases over a period of five years from January 2013 December 2017, 30 patients with tuberculosis of breast formed the study group. Maximum number of patients were in the age group of 21 - 30 years (56.7\%). The mean age of patients in our study group was 31 years. Breast tuberculosis is predominately a disease of young multiparous females with most patients between age group of 20 - 40 years. ${ }^{6}$ It is exceptional in teenage, postmenopausal women and men. ${ }^{7}$ It commonly affects women in their reproductive age group between 21 - 30 years similar to highest incidence of pulmonary tuberculosis reported in same age group. ${ }^{8}$ This may be because the female breast undergoes frequent changes during the period of activity and is more liable to trauma and infection. ${ }^{9}$ Risk factors are multiparity, lactation, trauma, past history of suppurative mastitis and AIDS. ${ }^{5}$ Out of 30 patients in our study, one was male and one patient had bilateral involvement of breasts. It is rare in males and is reported in $4 \%$ of cases. ${ }^{10,11}$ Bilateral involvement is uncommon (3\%).12 Lactating women are more susceptible to develop breast tuberculosis. This could be due to increased vascularity of breast during lactation, which facilitates infection and dissemination of bacilli. Shinde et al and Banerjee et al reported $7 \%$ and 33\% respectively of their patients suffering with breast tuberculosis to be lactating at the time of initial presentation. ${ }^{8,12}$ However, in our study only 5 patients $(16.7 \%)$ were lactating. Breast tuberculosis most commonly presents as a lump in central or upper outer quadrant of breast.13,14,15

In our study, most common presentation was solitary breast lump in upper outer quadrant. Only one patient had bilateral breast tuberculosis. In most of the studies, the most common clinical presentation of tuberculous mastitis is that of a solitary, ill defined, unilateral, hard lump situated in central or upper outer quadrant.6,8,16 Multiple lumps and bilateral involvement are uncommon and occur in less than $3 \%$ of patients. ${ }^{16,17}$ Seven patients in our study (23.4\%) had breast abscess as clinical manifestation. Two patients out of these seven presented with recurrent breast abscess, whereas rest of the five patients had poor response to surgical drainage and antibiotic coverage. Five patients $(16.7 \%)$ in our series had non-healing ulcer/ sinus with underlying lump. Breast abscess with poor response to drainage and antibodies, recurrent breast abscess with or without discharging sinus and tubercular ulcer over breast skin are other common presentations of breast tuberculosis. Deepa $\mathrm{H}$ et al in their study found breast abscess in (64.3\%) cases, breast lump mimicking carcinoma breast in $14.3 \%$ and fibrocystic disease in $21.4 \% .18$

Ziehl-Neelsen staining was done in seven cases of breast abscesses with suspicion of tuberculosis. Out of seven cases, acid fast bacilli were seen in only one case (14.2\%). Although, demonstration of acid fast bacilli on Ziehl-Neelsen staining and isolation of mycobacterium tuberculosis bacilli in culture is gold standard for diagnosing a case of tuberculosis, ${ }^{19}$ it requires at least 10,000 bacilli/mL for Ziehl-Neelsen stain to be positive for AFB and isolation of mycobacterium in culture takes time. ${ }^{20}$
In our study, FNAC was conclusive of tubercular pathology in 16 cases out of 29 undergoing FNAC (55.17\%). In patients where FNAC was inconclusive $(\mathrm{N}=13)$, biopsy of the lump/ margin of ulcer and sinus tract was suggestive of tuberculosis in all the patients $(100 \%)$. Demonstration of caseating granulomas on FNAC is sufficient enough to diagnose a case of tuberculosis. In countries where tuberculosis is endemic, the finding of granulomas in FNAC warrant empirical treatment for tuberculosis even in absence of positive AFB stain/ culture positivity. ${ }^{21,22}$ FNAC from breast lump can diagnose up to $73 \%$ of cases when both epithelial cell granulomas and necrosis are present. ${ }^{21}$ Histopathological examination of biopsy taken from lump, ulcer or sinus tract almost always confirms breast tuberculosis.8,21 According to Tewari et al, FNAC can diagnose breast tuberculosis in as many as three-quarter of cases. ${ }^{2}$ Khanna et al stated that $100 \%$ reliable diagnosis can be made by FNAC and/or histology. Ultrasonography helps to characterising nature of lump whether solid/ cystic and localise tissue for sampling. ${ }^{23}$ In one case with mastalgia and poorly localised lump, USG-guided percutaneous aspiration was positive for AFB on ZN staining. Mammography is not very helpful in diagnosing the tuberculous mastitis, as findings may mimic either fibrocystic disease in early stages and malignancy in advanced stage. ${ }^{8,23}$ Similarly, CT scan and MRI of breast is not very useful in diagnosis, but extent of disease in breast and extramammary spread can be defined. ${ }^{24}$ Nucleic acid amplification test like PCR is rapid and specific but has low sensitivity. 25

These may be helpful in cases with strong suspicion of tuberculosis with inconclusive FNAC and culture. Medical management with antitubercular drugs is the mainstay of treatment. Although, no specific guidelines are available for chemotherapy of breast tuberculosis, it generally follows guidelines used for pulmonary tuberculosis. Ten of our patients were treated with antitubercular drugs only, whereas seven patients were started on antitubercular drugs after drainage of breast abscess. Excision of lump followed by ATT was done in eleven patients. We used four drugs [HRZE] for two months in the intensive phase followed by two drugs [HR] for another four months. However, in two of our patients requiring excision of residual lump after 6 months of ATT, isoniazid and rifampicin were continued for another three months. All the patients responded to ATT and were followed up for six months after successful completion of treatment and were disease free. Success rate of medical therapy approaches $95 \%$ in most series with 6 months of ATT. ${ }^{6,8}$ Surgical intervention was needed in $14 \%$ of patients in some series either due to lack of response to chemotherapy or large painful ulcerative lesions involving entire breast.2,26

\section{CONCLUSION}

Tuberculosis of the breast is a rare entity. A variety of diagnostic modalities are needed to establish the diagnosis. ATT is the mainstay of treatment with surgical intervention needed in some cases.

\section{REFERENCES}

[1] Cooper A. Illustration of the diseases of Breast. Part I. London: Longman, Rees, Orme, Brown and Green 1829: p. 7. 
[2] Tewari M, Shukla HS. Breast tuberculosis, diagnosis, clinical features and management. Indian J Med Res 2005;122(2):103-10.

[3] Mirsaeidi SM, Masjedi MR, Mansouri SD, et al. Tuberculosis of the breast: report of four clinical cases and literature review. Eastern Mediterranean Health J 2007;13(3):670-6.

[4] Hamit HF, Ragsdale TH. Mammary tuberculosis. J R Soc Med 1982;75(10):764-5.

[5] Sharma PK, Babel AL, Yadav SS. Tuberculosis of breast (study of 7 cases). J Postgrad Med 1991;37(1):24-6, 26A.

[6] Jalali U, Rasul S, Khan A, et al. Tuberculosis mastitis. J Coll Physicians Surg Pak 2005;15(4):234-7.

[7] Gerbal R. A case of breast tuberculosis in women. These Paris 1964:665.

[8] Shinde SR, Chandawarkar RY, Deshmukh SP. Tuberculosis of the breast masquerading as carcinoma: a study of 100 patients. World J Surg 1995;19(3):379-81.

[9] Mukherjee $\mathrm{P}$, George $\mathrm{H}$, Maheshwar $\mathrm{HB}$, et al. Tuberculosis of Breast. J Indian Med Assoc 1974;62(12):410-2.

[10] Jaideep C, Kumar M, Khanna AK. Male breast tuberculosis. Postgrad Med J 1997;73(861):428-9.

[11] Morgan M. Tuberculosis of the breast. Surg Gynecol Obstet 1931;53:593-605.

[12] Banerjee SN, Ananthakrishnan N, Mehta RB, et al. Tuberculous mastitis: a continuing problem. World J Surg 1987;11(1):105-9.

[13] Gupta R, Gupta AS, Duggal N. Tubercular mastitis. Int Surg 1982;67(Suppl 4):422-4.

[14] Alagaratnam TT, Ong GB. Tuberculosis of the breast. Br J Surg 1980;67:125-6.
[15] Shukla HS, Kumar S. Benign breast disorders in nonwestern populations: Part II - Benign breast disorders in India. World J Surg 1989;13(6):746-9.

[16] Banerjee A, Green B, Burke M. Tuberculosis and granulomatous mastitis. Practitioner 1989;233(1469):754-6.

[17] Elmrabet F, Ferhati D, Amenssag L, et al. Breast tuberculosis. Med Trop (Mars) 2002;62(1):77-80.

[18] Deepa H, Vijay S, Jai MP, et al. Tubercular Mastitis is common in Garhwal Region of Uttrakhand: clinico pathological features of 14 cases. J Clin Diag Res 2011;5(8):1569-73.

[19] Gupta PP, Gupta KB, Yadav RK, et al. Tuberculous mastitis: a review of seven consecutive cases. Indian J Tub 2003;50:47-50.

[20] Kalac N, Ozkan B, Bayiz H, et al. Breast Tuberculosis. Breast 2002;11(4):346-9.

[21] Khanna R, Prasanna GV, Gupta P, et al. Mammary tuberculosis: report of 52 cases. Post Grad Med J 2002;78(921):422-4.

[22] Malhotra R. Fine needle aspiration cytology, diagnosis of Tuberculous Mastitis. Indian J Pathol Microbiol 2004;47:377-80.

[23] Popli MB. Pictorial essay: tuberculosis of the breast. Indian J Radiol Imag 1999;9(3):127-32.

[24] Chung SY, Yang I, Bae SH, et al. Tuberculous abscess in retromammary region: CT findings. J Comput Assist Tomogr 1996;20(5):766-9.

[25] Sriram KB, Moffatt D, Stapledon R. Tuberculosis infection of the breast mistaken for granulomatous mastitis: a case report. Caes J 2008;1(1):273.

[26] Elsiddig KE, Khalil EA, Elhag IA, et al. Granulomatous mammary, disease: ten years' of experience with fine needle aspiration cytology. Int J Tubex Lung Dis 2003;7(4):365-9. 